Contraditório nas Decisões Paradigmáticas: Julgamentos Repetitivos e Incidente de Assunção de Competência

Dissertação de Mestrado

Orientador: Professor Dr. Marcelo José Magalhães Bonizzi

UNIVERSIDADE DE SÃO PAULO

FACULDADE DE DIREITO

Departamento de Direito Processual

São Paulo - SP

2020 



\section{Contraditório nas Decisões Paradigmáticas: Julgamentos Repetitivos e Incidente de Assunção de Competência}

Dissertação de Mestrado apresentada à Banca Examinadora do Programa de PósGraduação em Direito, da Faculdade de Direito da Universidade de São Paulo, como exigência parcial para obtenção do título de mestre em Direito, na área de concentração de Direito Processual, sob orientação do Prof. Dr. Marcelo José Magalhães Bonizzi.

\section{UNIVERSIDADE DE SÃO PAULO}

\section{FACULDADE DE DIREITO}

Departamento de Direito Processual

São Paulo - SP 
Catalogação da Publicação

Serviço de Biblioteca e Documentação

Faculdade de Direito da Universidade de São Paulo

Azevedo, Fernanda Kontic da Rocha

Contraditório nas decisões paradigmáticas: julgamentos

repetitivos e Incidente de Assunção de Competência / Rocha Azevedo, Fernanda Kontic da; orientador Prof. Marcelo José Magalhães Bonizzi -- São Paulo, 2020.

$143 p$.

Dissertação (Mestrado - Programa de Pós-Graduação em Direito Processual) - Faculdade de Direito, Universidade de São Paulo, 2020.

1. Contraditório. 2. Precedentes. 3. Incidente de Assunção de Competência. Incidente de Resolução de Demandas Repetitivas. Recursos Repetitivos. I. Bonizzi, Prof. Dr. Marcelo José Magalhães orient. II. Título.

A Banca Examinadora, abaixo assinada, aprova a Dissertação 


\title{
Contraditório nas Decisões Paradigmáticas: Julgamentos Repetitivos e Incidente de Assunção de Competência
}

\author{
elaborada por \\ FERNANDA KONTIC DA ROCHA AZEVEDO \\ como requisito parcial para a obtenção do grau de \\ MESTRE EM DIREITO PROCESSUAL
}

BANCA EXAMINADORA: 
Ao meu pai,

Dr. Alberto Gomes da Rocha Azevedo Jr., meu grande professor. 


\section{AGRADECIMENTOS}

Agradeço, primeiramente, ao meu orientador, Dr. Marcelo José Magalhães Bonizzi, pela oportunidade e confiança em mim depositada. Sempre solícito e atencioso, sua orientação foi indispensável para o meu aprendizado.

Também, à professora Teresa Arruda Alvim, pelas aulas de graduação e pela oportunidade de ter sido sua assistente. Foi ela quem me apresentou o Processo Civil, matéria que tanto me interessa.

Aos meus pais, que sempre priorizaram a minha formação e felicidade. Ao meu saudoso pai, meu maior e eterno exemplo, e à minha mãe, que viveu tudo isso comigo.

Ao Milton Dotta Neto, meu marido, meu eterno companheiro, que esteve comigo a cada dia. Que nós dois sigamos sempre juntos e em frente.

Àqueles que conheci durante o Mestrado e que me deram tanto apoio, especialmente Roberto Barroco, Giovanna del Nero, Marcely Rodrigues, Cristhiane Bessas e Bruna Tourinho.

Não poderia de deixar de mencionar aqueles que estão comigo diariamente, no escritório Rocha Azevedo, Gomes e Lara: meu tio Antonio, minha prima Luiza e os sócios Ricardo, Pedro e Tácito, que me permitiram a dedicação ao Mestrado. 

"Quando estiver em dúvida, escolha a opção que Ihe parecer mais difícil, normalmente é a melhor." (Autor desconhecido) 

ROCHA AZEVEDO, Fernanda Kontic da. Contraditório nas decisões paradigmáticas: julgamentos repetitivos e Incidentes de Assunção de Competência. 143p. Dissertação (Mestrado em Direito Processual) - Departamento de Direito Processual da Faculdade de Direito. Universidade de São Paulo. São Paulo - USP. São Paulo, 2020.

\section{RESUMO}

As decisões paradigmáticas são aquelas proferidas em sede de julgamento por amostragem. No Direito Processual Civil atual há três técnicas dessa espécie: os Recursos Especiais e Extraordinários Repetitivos, o Incidente de Resolução de Demandas Repetitivas e o Incidente de Assunção de Competência. Em todas elas os efeitos da decisão podem afetar não só os sujeitos do processo, como também terceiros e, quiçá, toda a sociedade. Dessa forma, para que haja certa garantia de participação e acesso à justiça, é necessário ampliar o contraditório. Existem mecanismos para isso, notadamente a participação de amicus curiae e as audiências públicas. Juntamente com a participação deve ser garantido aos interessados o poder de influência, que tem umbilical relação com a motivação da decisão paradigmática. Da mesma maneira, para a aplicação da decisão paradigmática, deve ser proporcionado às partes o debate, permitindo a manifestação acerca da utilização do paradigma. O presente estudo aborda a importância e os limites da ampliação do contraditório nos julgamentos por amostragem.

Palavras-chave: Contraditório. Precedentes. Incidente de Assunção de Competência. Incidente de Resolução de Demandas Repetitivas. Recursos Repetitivos. 

ROCHA AZEVEDO, Fernanda Kontic da. Contraditório nas decisões paradigmáticas: julgamentos repetitivos e incidentes de assunção de competência. 143p. Dissertation (Master in Procedural Law) - Department of Procedural Law. Faculty of Law. University of São Paulo. São Paulo - USP. São Paulo, 2020.

\begin{abstract}
Paradigmatic decisions are those made by judging by sampling. In current civil procedural law there are three techniques of this kind: repetitive appeals, the repetitive claims resolution incident, and the assumption of jurisdiction. In the three techniques, the effects of the decision affect not only the parties, but other people, in some cases, the whole society. Thus, in order to have a certain guarantee of participation and access to justice, it is necessary to o broaden the debate. There are mechanisms for this, notably the participation of amicus curiae and public hearings. Along with participation, the possibility of influence should be guaranteed to the ones who have interested on the opinion, and there is an strong relation between the reasoning of the paradigmatic decision. Likewise, for the application of the paradigm, the parties should be allowed to debate, manifesting about the use of the precedent This paper will study the importance and the limits of the widening of the contradictory in the judgments by sampling.
\end{abstract}

Key words: Contradictory. Precedent. Assumption of Competence. Repetitive Demands Resolution Incident. Repetitive Resources. 



\section{LISTA DE SIGLAS}

$\begin{array}{ll}\text { ABPI } & \text { Associação Brasileira da Propriedade Intelectual } \\ \text { AGROBIO } & \begin{array}{l}\text { Associação de Empresas de Biotecnologia, Agricultura e } \\ \text { Agroindústria }\end{array} \\ \text { BNPR } & \begin{array}{l}\text { Banco Nacional de Demandas Repetitivas e Precedentes } \\ \text { Obrigatórios }\end{array} \\ \text { CDC } & \text { Código de Defesa do Consumidor } \\ \text { CNJ } & \text { Conselho Nacional de Justiça } \\ \text { CVM } & \text { Comissão de Valores Mobiliários } \\ \text { ENFAM } & \text { Escola Nacional de Formação e Aperfeiçoamento de Magistrado } \\ \text { IAC } & \text { Incidente de Assunção e Competência } \\ \text { IPTU } & \text { Imposto Predial e Territorial Urbano } \\ \text { IRDR } & \text { Incidente de Resolução de Demandas Repetitivas } \\ \text { ITBI } & \text { Imposto sobre a Transmissão de Bens Imóveis e de Direitos } \\ \text { OAB } & \text { Ordem dos Advogados do Brasil } \\ \text { OAB } & \text { Organização dos Advogados do Brasil } \\ \text { STF } & \text { Supremo Tribunal Federal } \\ \text { STJ } & \text { Superior Tribunal de Justiça } \\ \text { TR } & \text { Taxa Referencial } \\ \text { TUSD } & \text { Tarifa de Uso do Sistema de Distribuição } \\ \text { TUST } & \text { Tarifa de Uso da Transmissão }\end{array}$





\section{SUMÁRIO}

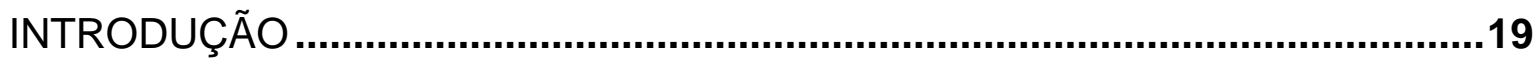

1 ACESSO À JUSTIÇA E LITIGIOSIDADE REPETITIVA .................................25

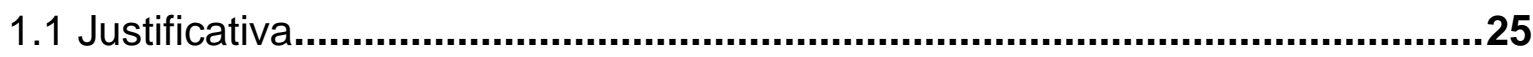

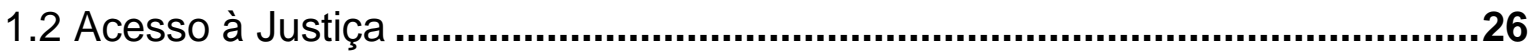

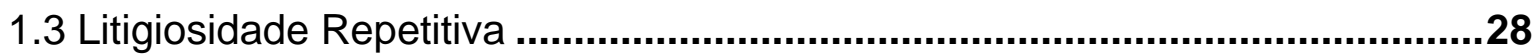

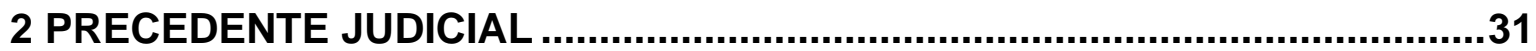

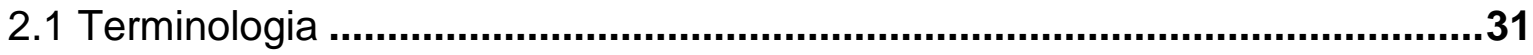

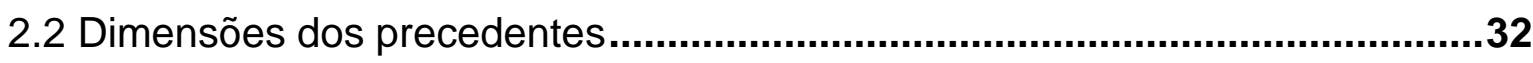

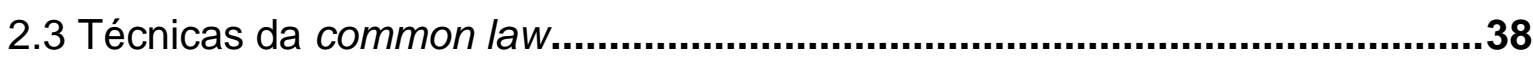

2.4 APLICAÇÃO DOS PRECEDENTES JUDICIAIS NO BRASIL..........................40

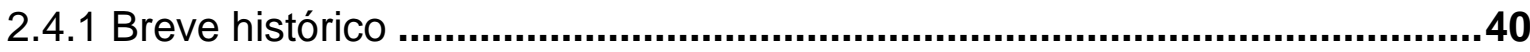

2.4.2 O Código de Processo Civil de 1973 e as Reformas ...................................43

2.4.3 O Código de Processo Civil de 2015 .........................................................45

2.5 A utilização de precedentes não torna o Brasil país de common law .............49

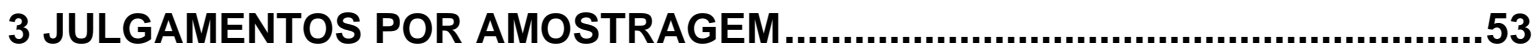

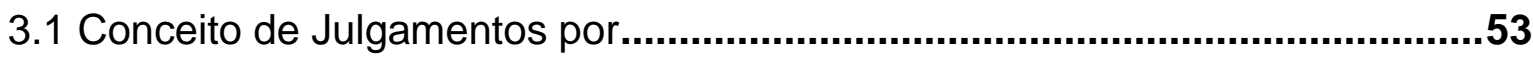

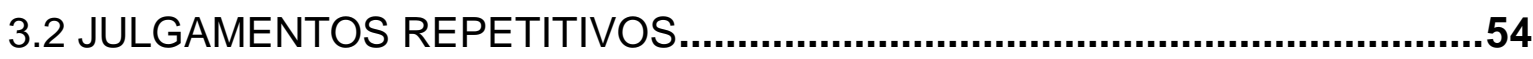

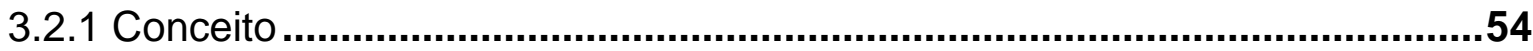

3.2.2 Incidente de Resolução de Demandas Repetitivas.....................................56

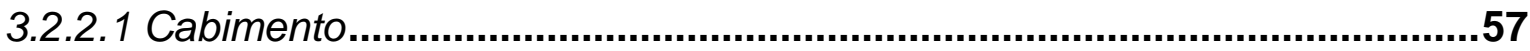

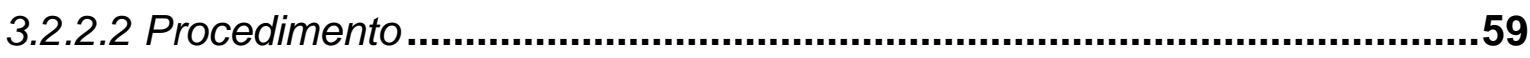

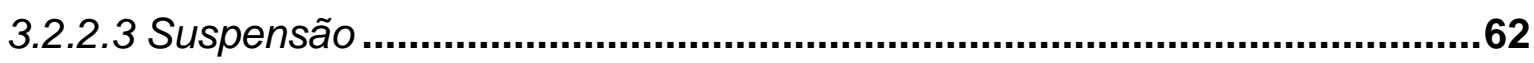

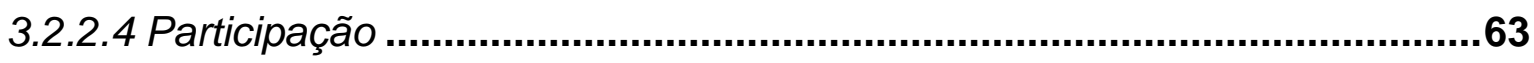

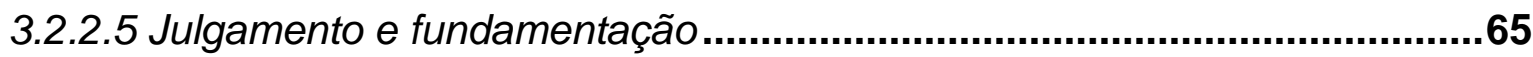

3.2.2.6 Interposição de Recurso Especial ou Extraordinário..................................66

3.2.2.7 Vinculação...................................................................................................66

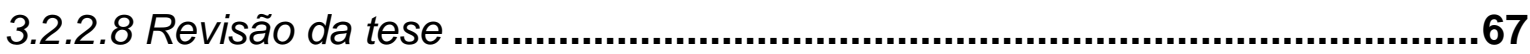

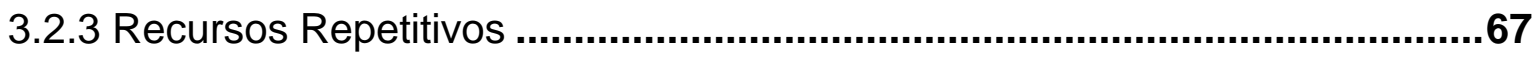

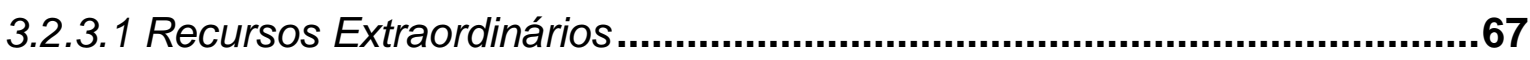

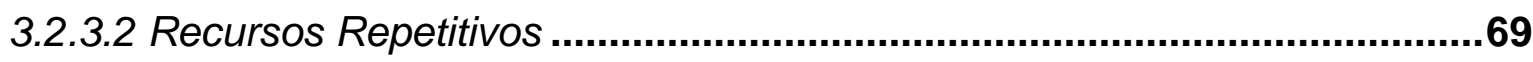

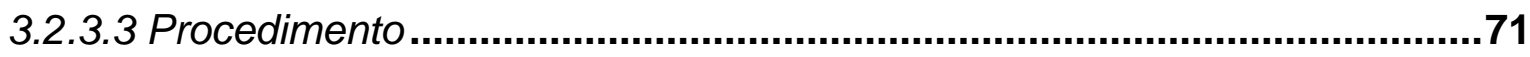

3.2.3.4 Aplicação da tese e vinculação .............................................................74 


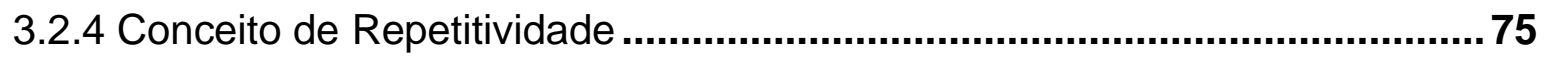

3.2.5 Julgamentos Repetitivos e Ações Coletivas ...............................................77

3.3 INCIDENTE DE ASSUNÇÃO DE COMPETÊNCIA (IAC) ...............................79

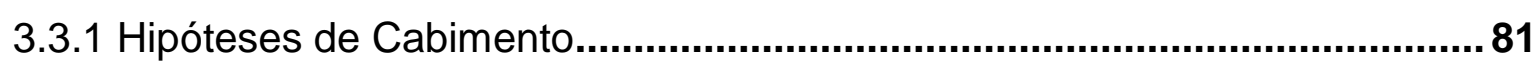

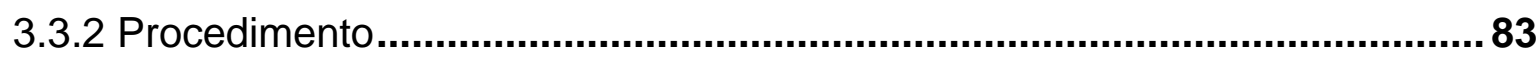

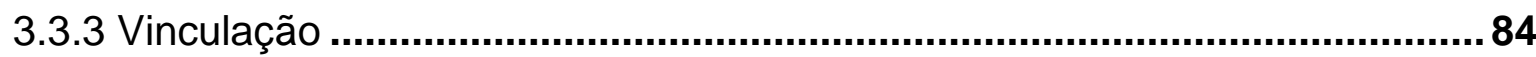

3.3.4 Os Incidentes de Assunção de Competência admitidos no STJ.................... 85

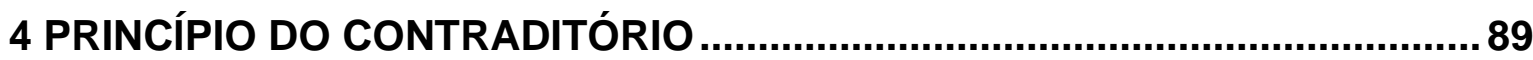

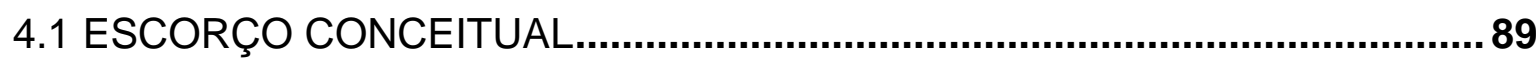

4.2 O CONTRADITÓRIO NO CÓDIGO DE PROCESSO CIVIL DE 2015 .............91

4.2.1 Arts. 9o e 10 do Código de Processo Civil de 2015 ......................................91

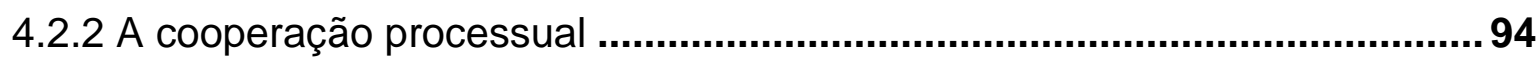

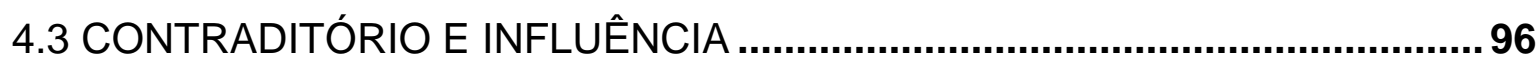

4.3.1 A influência como finalidade do contraditório..............................................96

4.3.2 A motivação das decisões judiciais como verificação do exercício do

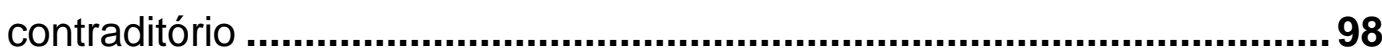

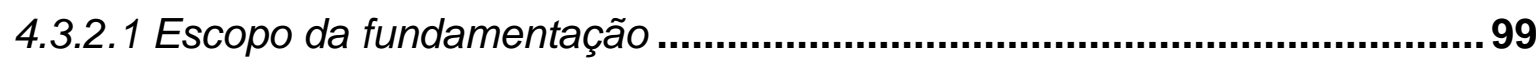

4.3.3 Dever de fundamentação, segundo o art. 489, $\S 1^{\circ}$ do CPC ........................100

5 CONTRADITÓRIO E DECISÕES PARADIGMÁTICAS ....................................103

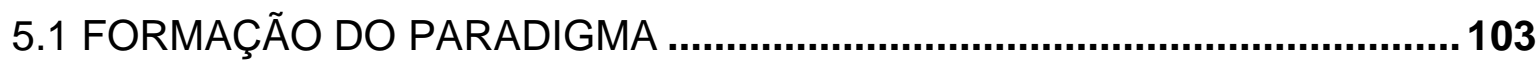

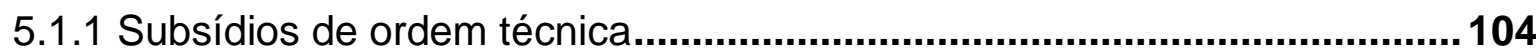

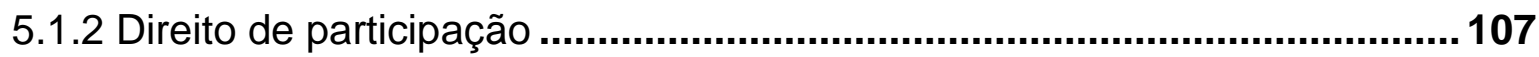

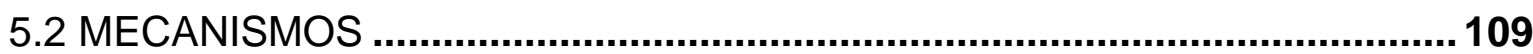

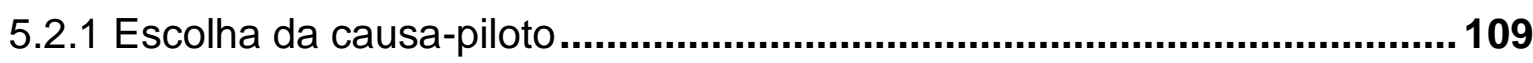

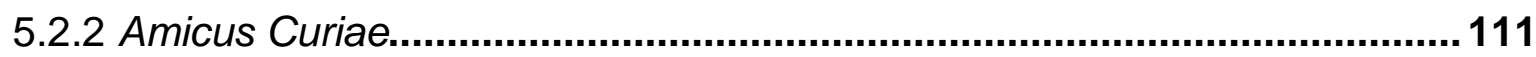

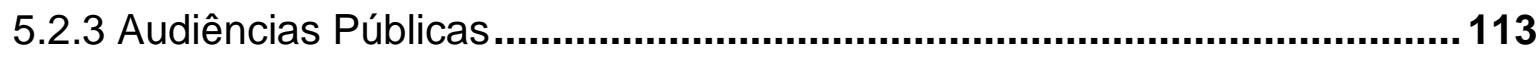

5.3 HIPÓTESES DE AMPLIAÇÃO DO CONTRADITÓRIO .................................115

5.4 FUNDAMENTAÇÃO DO PARADIGMA ….................................................119

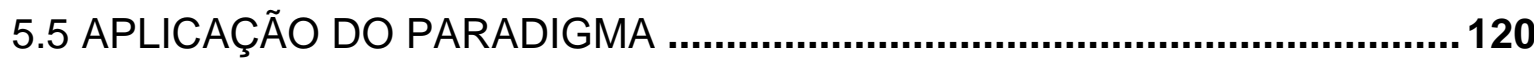

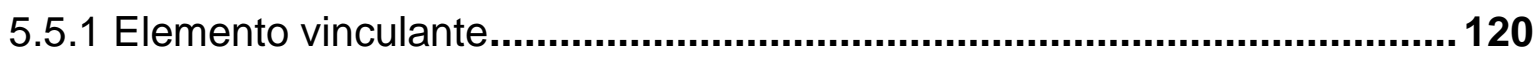

5.5.2 Aspecto temporal da vinculação - Modulação.......................................... 122

5.5.3 O contraditório na aplicação dos precedentes ............................................124

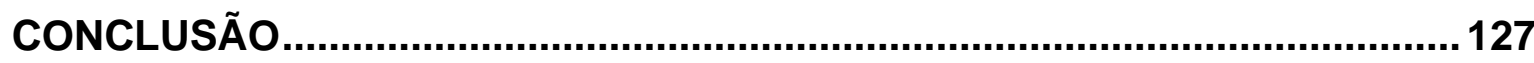

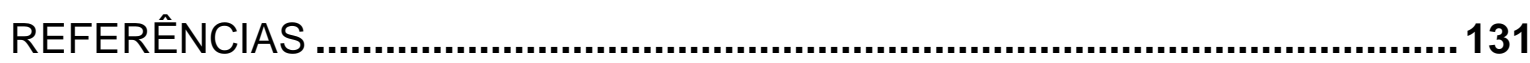




\section{INTRODUÇÃO}

O presente estudo tem como objeto o contraditório para a formação e aplicação das decisões paradigmáticas. Para as finalidades da pesquisa, consideram-se decisões paradigmáticas os Acórdãos dos julgamentos por amostragem, quais sejam, os Julgamentos Repetitivos e o Incidente de Assunção e Competência (IAC).

O referido assunto relaciona-se à litigiosidade repetitiva e, também, aos precedentes - uma das técnicas utilizadas pelo legislador do Código de Processo Civil de 2015 para lidar com a litigiosidade.

Não é pretensão deste estudo - e tampouco se acredita ser possível - o diagnóstico preciso de uma única causa para a litigiosidade repetitiva e o congestionamento judiciário.

O tema é debatido pela doutrina há algumas décadas, anteriormente à promulgação da Constituição Federal de 1988 (CF/88). Cita-se, como exemplo, o texto escrito por Alfredo Buzaid1', publicado no ano de 1972, narrando impossibilidade de o Supremo Tribunal Federal (STF) lidar com a sobrecarga de processos já na década de 1950 .

Parte da litigância repetitiva, consiste nos "conflitos de massa". Tais litígios refletem modificações nas relações jurídicas, advindas do pós-revolução industrial. No período da revolução, em razão de alterações na produção, iniciou-se processo de massificação das relações. Contratos anteriormente confeccionados "sob medida", cederam espaço a contratos de adesão². A existência de relações massificadas -, essencialmente idênticas entre si -, seja entre consumidor e fornecedor, entre tributante e contribuinte, grandes empregadores e trabalhadores, implica, em sua maioria, na existência de repetitivos conflitos de massa.

Simultaneamente, como reação aos Regimes Totalitários e à Segunda Guerra Mundial, iniciou-se um processo de reconhecimento e positivação de

\footnotetext{
${ }^{1}$ BUZAID, Alfredo. A crise do Supremo Tribunal Federal. Estudos de Direito. São Paulo: Saraiva, 1972.

2 V. BENJAMIN, Antônio Herman V. A insurreição da aldeia global contra o processo civil clássico: apontamentos sobre a opressão e a libertação judiciais do meio ambiente e do consumidor In: MILARÉ, Édis (coord.). Ação civil pública - Lei 7.347/85: reminiscências e reflexões após dez anos de aplicação. São Paulo: Editora Revista dos Tribunais, 1995, p. 78.
} 
"novos" direitos, notadamente pelos tratados e pactos de Direitos Humanos da Organização das Nações Unidas.

Desde 1948, ano em que foi promulgada a Declaração Universal de Direitos Humanos, foram reconhecidos muitos direitos - em sua maioria coletivos - por exemplo, o direito ao meio ambiente sadio, a proteção às pessoas com deficiência, à criança e ao adolescente, ao idoso, entre outros.

Concomitantemente, conferiu-se à população maior acesso à justiça para efetivação daqueles direitos. Esse movimento contou com a notória influência de Mauro Cappelletti e de Bryant Garth", autores da obra "Acesso à Justiça”. A referida obra é fruto do chamado "Projeto Florença", que consistiu num estudo multidisciplinar, observando-se diversos ordenamentos jurídicos com o objetivo de planejar meios de fornecer aos cidadãos o alcance dos seus direitos pelo Poder Judiciário ${ }^{4}$.

Sob influência desses ideais, foi editada, no Brasil, a Lei da Ação Civil Pública $^{5}$, que visou à proteção dos direitos metaindividuais, e concebeu aos Juizados de Pequenas Causas ${ }^{6}$, a garantia para apreciação de conflitos de menor relevância econômica.

Pouco tempo depois o legislador Constituinte de $1988^{7}$ atribuiu relevância constitucional a uma série dos chamados direitos coletivos lato sensu, cita-se, como

\footnotetext{
3 "Para quem o acesso à justiça é tido como o requisito fundamental - o mais básico dos direitos humanos - de um sistema jurídico moderno e igualitário que pretenda garantir, e não apenas proclamar o direito de todos." (CAPPELLETTI, Mauro; GARTH, Bryant. Acesso à justiça. Trad. de Ellen Gracie Northfleet. Porto Alegre: Fabris, 1988, p. 8).

${ }^{4}$ Explica Ada Pellegrini Grinover: "A partir da declaração universal dos direitos do homem, em todas as constituições os valores fundamentais da justiça e da dignidade humana foram interiorizados pelos Estados, prenunciando-se o advento da era das constituições. Ao longo desse processo, consolidam-se as ideias em torno do controle da constitucionalidade pelos Tribunais (constitucionais ou comuns) e o Judiciário assume uma posição mais ativa [...] o Judiciário assume a função de outros Poderes, em relação à observância da Constituição e da efetivação de direitos fundamentais por ela garantidos. É uma função de garantia. A função de garantia é voltada a colmatar, em especial no caso brasileiro, as lacunas contingenciais, que como reconhecido na doutrina, são sempre reparáveis, pois se trata de aplicar a norma constitucional." (GRINOVER, Ada Pellegrini. Ensaio sobre a processualidade: fundamentos para uma nova teoria geral do processo. Brasília: Gazeta Jurídica, 2016, p. 124).

${ }^{5}$ BRASIL. Lei no 7.347, de 24 de julho de 1985. Disciplina a ação civil pública de responsabilidade por danos causados ao meio-ambiente, ao consumidor, a bens e direitos de valor artístico, estético, histórico, turístico e paisagístico (VETADO) e dá outras providências. Disponível em: http://www.planalto.gov.br/ccivil_03/Leis/L7347orig.htm. Acesso em: 12 set. 2019.

${ }^{6}$ Os Juizados de Pequenas Causas foram criados pela Lei n. 7.244, de 7 de novembro de 1984, para julgamento de conflitos de menor importância econômica. Tamanha foi a sua efetividade que tiveram a sua competência estendida pela Lei 9.099, de 26 de setembro de 1995.

7 Relevante ressaltar que a crise dos Tribunais em razão do número exorbitante de processos não é algo recente, causado pela promulgação da Constituição de 1988. A impossibilidade de o STF lidar com a litigiosidade já era preocupação dos juristas desde a década de 1950, sendo até razão
} 
exemplo, alguns: defesa do consumidor (art. 5ำ XXXI, CF/88), direito ao meio ambiente saudável e ecologicamente equilibrado (art. 225, CF/88), direitos da criança e do adolescente (art. 227, CF/88) e direitos das pessoas com deficiência (arts. 24, XIV; 208, III; 227, § $1^{\circ}$, I e $§ 2^{\circ}, \mathrm{CF} / 88$ ).

Posteriormente, em 1990, foi editado o Código de Defesa do Consumidor $(C D C)^{8}$, que representou uma inovação na legislação processual, consagrando, conjuntamente com a Lei da Ação Civil Pública, mencionada anteriormente, o microssistema processual coletivo.

O novo estatuto aperfeiçoou mecanismos de defesa em juízo de direitos metaindividuais, inserindo no ordenamento a tutela específica para a obrigação de fazer (art. 84) e a ampliação subjetiva da coisa julgada que, pela lei, poderia ser erga omnes (arts. 103 e ss). Assim, por remissão expressa, no art. 90, o CDC, conjuntamente com a Lei da Ação Civil Pública, formou o microssistema processual coletivo.

Essa série de "novos" direitos materiais, bem como a sua viabilização aos cidadãos em busca desses direitos junto ao Estado, na sua função jurisdicional, agravou a crise do Judiciário, uma vez que se deu vazão à "litigiosidade contida" 9 .

Para que fosse possível abarcar todas as demandas, e que se prestigiasse a igualdade e a razoável duração do processo, recorreu-se à utilização de técnicas de utilização de precedentes, notadamente, aos julgamentos por amostragem.

A ideia do precedente jurisprudencial como fonte do Direito não é nova no Direito pátrio. Nos capítulos 2 e 3 deste estudo apresenta-se um breve histórico que permite conhecer a origem lusitana do costume de observância da orientação pretoriana.

Ainda sob a égide do Código de Processo Civil de 1933, o STF passou a editar as súmulas persuasivas. Durante a vigência do Código de Processo Civil de 1973, especialmente após os anos 2000, positivaram-se institutos (e.g. súmula vinculantes, súmula impeditiva de recurso, julgamento de recursos repetitivos) que,

da criação do Superior Tribunal de Justiça pela Constituição de 1988. Nesse sentido, ver texto do ministro Alfredo Buzaid (BUZAID, Alfredo. Op. cit., 1972).

8 BRASIL. Lei n. 8.078, de 11 de setembro de 1990. Dispõe sobre a proteção do consumidor e dá outras providências. Disponível em: http://www.planalto.gov.br/ccivil_03/leis//8078.htm. Acesso em: 12 set. 2019.

9 Conceito de Kazuo Watanabe. Mais em: WATANABE, Kazuo. Cultura da sentença e cultura da pacificação. In: SALETTI, Achille (Org.). Estudos em homenagem à Professora Ada Pelegrini Grinover. São Paulo, 2005, pp. 684-90. 
de certa forma, vinculavam os órgãos judiciais inferiores, ou, ao menos, tinham forte impacto na persuasão do julgador.

O legislador do Código Processo Civil, de 2015, fortaleceu e criou novos instrumentos, a fim de implantar um regime de precedentes adaptado a tradição jurídica brasileira .

$\mathrm{O}$ art. 927, do CPC, estabelece aos julgadores obrigação de seguirem determinadas manifestações judiciais, dentre elas os acórdãos do Incidente de Resolução de Demandas Repetitivas (IRDR), dos Recursos Excepcionais sob Regime Repetitivos e o do Incidente de Assunção de Competência (IAC).

Esses todos, expressos no inc. III do referido artigo, guardam a semelhança de serem procedimentos por amostragem. Isso significa que se escolhe uma causa (dentre várias, no caso dos julgamentos repetitivos, ou uma singular, cuja matéria sob discussão seja de repercussão social, no $(A C)$, para conhecimento e julgamento, aplicando-se tese jurídica fixada a demandas do mesmo objeto.

Neles os julgadores conhecem e julgam do processo ou recurso, com o objetivo de fixar tese ${ }^{10}$ de direito, que será aplicada a outras demandas idênticas. Distinguem-se, portanto, do biding precedent da common law. Naquela, ao julgar o caso, o juiz de common law visa a apenas dirimir aquele conflito específico, aplicando os princípios de direito e costume. Por ventura, em momento posterior, a decisão poderá ser aplicada, analogicamente, a outro caso concreto, quando será identificado a ratio decidendi, princípio de direito utilizado para, extraindo-se uma regra geral11.

Não se confundem, também, com as outras hipóteses do art. 927, do CPC/15, uma vez que nas súmulas e orientações de Tribunais são frutos reiteradas decisões. O tempo e diversidade de processos confere aos julgadores acesso a

\footnotetext{
10 O termo "tese" é utilizado nos acórdãos de julgamento de recursos repetitivos pelo STJ. Trata-se de enunciado que contém a interpretação jurídica fixada pelo Tribunal por ocasião do julgamento do recurso.

${ }^{11}$ Conforme trata José Rogério Cruz e Tucci, em obra sobre o tema, "O precedente, então, nasce como uma regra de um caso e, em seguida, terá ou não o destino de tornar-se a regra de uma série de casos análogos." (CRUZ E TUCCI, José Rogério. Precedente judicial como fonte do direito. São Paulo: Revista dos Tribunais, 2004). No mesmo sentido, afirma Georges Abboud: "Destarte, ontologicamente, o precedente constitui decisão judicial proferida para solucionar caso concreto, ele nunca pode pretender nascer desde sempre como precedente. Assim, a aptidão dele para construir critério normativo apto a solucionar novos casos, dependerá, inevitavelmente do processo histórico referente à sua futura aplicação." (ABBOUD, Georges. Precedente Judicial versus Jurisprudência dotada de efeitos vinculante. In: WAMBIER, Teresa Arruda Alwim (Org.). Direito Jurisprudencial. São Paulo: Revista dos Tribunais, 2012a, p. 514).
} 
multiplicidade de argumentos e fatos, moldando a sua posição. Da mesma forma como no common law há dois momentos: o de julgamento e outro posterior, em que se verifica a regra geral a ser seguida.

Posto isso, é quase intuitiva a afirmação de que nos procedimentos do art. 927, III, do CPC, se deve promover mais elementos aos julgadores para cognição. Referida cognição é promovida pelo contraditório. Existem mecanismos para isso, tipicamente a possibilidade de intervenção de amicus curiae e agendamento de audiências públicas. Porém, questiona-se: a validade do paradigma é condicionada à influência e à manifestação de interessados possíveis no assunto - os chamados "litigante sombra"12? Haverá sempre a necessidade de participação, seja por audiências públicas ou intervenção como amicus curiae?

Ainda, no momento posterior, a aplicação do paradigmas, ou seja, das teses firmadas nos recursos repetitivos, IRDR e IAC, será automática? Como será promovido o debate e ônus argumentativo das partes?

Esses os questionamentos que o presente estudo se propõe a buscar as respostas.

12 O termo "litigantes-sombras" foi utilizado pelo ministro Herman Benjamin, no voto vencido no REsp. n. 911.802-RS, referente à cobrança de assinatura básica pelas empresas de telefonia. $\mathrm{O}$ ministro, referindo-se aos consumidores, que seriam afetados, mas que não puderam influenciar na decisão, assim se manifestou: "[...] a voz dos consumidores não se tenha feito ouvir. Não lastimo somente o silêncio de D. Camila Mendes Soares, mas, sobretudo, a ausência, em sustentação oral, de representantes dos interesses dos litigantes-sombra, todos aqueles que serão diretamente afetados pela decisão desta demanda, uma gigantesca multidão de brasileiros [...]" (STJ. Superior Tribunal de Justiça. Recurso Especial no 911.802-RS. Disponível em: http://www.mp.go.gov.br/portalweb/hp/4/docs/stj_telefonia_assinatura_basica.pdf. Acesso em: 12 set. 2019). 


\section{CONCLUSÃO}

Abordou-se, neste estudo, o contraditório na formação e aplicação das decisões paradigmáticas, ou seja, aquelas produzidas em sede de IRDR, recursos repetitivos e IAC. Tais decisões, nos termos do art. 927, III, do CPC, devem ser observadas pelos órgãos do Judiciário, são, portanto, precedentes.

O regime da civil law, especialmente o Direito brasileiro, não é incompatível com o respeito a decisões judiciais ou a precedentes. A observância à interpretação do Judiciário acerca da legislação é costume desde o Direito lusitano, sendo referência os assentos.

Mesmo na concepção positivista de Hans Kelsen, outorgava-se ao juiz a interpretação autêntica do texto legal. Atualmente, sob influência de ideias póspositivistas ou constitucionalistas, entende-se ser múnus do Judiciário o dever de garantia de direitos, ou seja, o dever de fazer valer os direitos humanos. Em paralelo, muito em razão, mas não somente, dos ideais de acesso à justiça, o número de litígios cresceu em progressão geométrica.

Como consequência, o Judiciário passou a receber, também, demandas versando questões jurídicas relevantes, de interesse social, como, por exemplo, a questão da possibilidade de união homoafetiva e as demandas repetitivas.

A criação de técnicas de julgamento por amostragem, que têm característica de demandas objetivas, foi uma das soluções. Elas permitem que os julgadores analisem uma só vez temas repetitivos, ou de relevante questão de direto, fixando uma tese, que será aplicada a casos idênticos.

Para qualidade dessas decisões, é relevante a ampliação do contraditório. Isso significa tanto o aumento da participação, permitindo a intervenção de interessados, como a oitiva de pessoas com experiencia. O que pode ser feito pela intervenção de amicus curiae, requisição de pareceres de experts e, também, com o agendamento de audiência pública.

O reconhecimento de que, de certa maneira, o Judiciário cria direito, justifica a ampliação do contraditório. Além da impossibilidade de a lei prever todas as situações, a velocidade das inovações e consequentes mudanças nas dinâmicas sociais, implica "novas" relações jurídicas, que necessitam ser disciplinadas. 
É o exemplo dos direitos autorais na reprodução de música e filmes via streaming, da tecnologia do credit score, de biomedicina ou transplantes.

O contraditório deve ser ampliado nessas situações, tanto para que 0 Judiciário possa compreender as inovações, como para que possa averiguar o posicionamento de grupos da sociedade a respeito dos temas.

A manifestação e direito de influência nas decisões judiciais não implica que o Judiciário deva decidir conforme a vontade da maioria. Não é essa a função do Judiciário, mas sim, de aplicação do direito.

Os julgamentos repetitivos e IAC, tema deste estudo, são técnicas de julgamento aptas a lidar com essas "novas" demandas. Os primeiros são apropriados para o gerenciamento de conflitos de massa, bem como questões jurídicas recorrentes. O IAC, por sua vez, é indicado nas relevantes questões de Direito, com grande repercussão social.

Dessa maneira, é conveniente que o Judiciário, nos hard cases, em questões demasiadamente técnicas ou em questões sensíveis à opinião popular, promova audiências públicas. A audiência pública é um instrumento que permite a oralidade e ampliação do debate, promovendo ao jurisdicionado a sensação que pôde influenciar no convencimento do juiz. É meio de promover o acesso à justiça, bem como representatividade dos chamados litigantes sombras.

Não apenas na formação do precedente deve ser oportunizado o contraditório. Uma vez fixado o paradigma, ele será ponto de partida para demandas futuras, cabendo às partes manifestarem-se a respeito da aplicabilidade ou não no caso em tela, conforme o art. 10, do CPC.

Esse ensejo de contraditório dá a parte o devido acesso à justiça. Explicase: se há discussão do cabimento ou não do precedente ao caso concreto é provável que a parte não tenha se manifestado no procedimento formador do paradigma.

Contudo, como visto anteriormente, a ausência de participação não gera qualquer vício no paradigma, não sendo apta a afastar sua imperiosidade. Dessa forma, a possibilidade de se opor e demonstrar eventual inaplicabilidade daquele paradigma ao seu litígio, assegura ao sujeito o direito de influenciar no convencimento para o resultado do "seu" processo, o que será verificado pela fundamentação. 
Em síntese, admitindo-se há certa criatividade de direito pelo Judiciário, e sendo os julgamentos repetitivos e IAC procedimentos propícios a tal criatividade, é conveniente em alguns casos ampliar o contraditório.

O contraditório na formação e na aplicação dos paradigmas é meio de fornecer aqueles que não puderam participar do procedimento acesso à justiça. Isso porque assegurou a eles a possibilidade de influência, obtendo resposta do Judiciário. 



\section{REFERÊNCIAS}

ABBOUD, Georges. Precedente Judicial versus Jurisprudência dotada de efeitos vinculante. In: WAMBIER, Teresa Arruda Alvim (Org.). Direito Jurisprudencial. São Paulo: Revista dos Tribunais, 2012.

ABBOUD, Georges. STF vs. vontade da maioria: as razões pelas quais a existência do STF somente se justifica se ele for contramajoritário. São Paulo: Revista dos Tribunais, v. 921, jul. 2012.

ALEXY, Robert. Conceito e validade do Direito. Tradução de Gercélia Batista de Oliveira Mendes. São Paulo: Martins Fontes, 2009.

ALVIM, Teresa Arruda. Nulidades do processo e da sentença. 10. ed. São Paulo: Revista dos Tribunais, 2019a.

ALVIM, Teresa Arruda. STJ acerta ao fixar tese antes de julgar recursos repetitivos. 2019b. Disponível em: https://www.conjur.com.br/2019-jun-05/teresa-arruda-alvimstj-acerta-fixar-tese-antes-julgar-repetitivo. Acesso em: 6 jun. 2019.

ALVIM, Teresa Arruda. Modulação na alteração da jurisprudência firme e de precedentes vinculantes. São Paulo: Revista dos Tribunais, 2019c.

ASPERTI, Maria Cecília de Araújo. Recursos repetitivos e incidente de resolução de demandas repetitivas: uma análise da perspectiva do acesso à Justiça e da participação no processo. Rio de Janeiro: Lumen Juris, 2018.

ASSIS, Araken de. Manual dos recursos. 6. ed. rev., atual. e ampl. São Paulo: Revista dos Tribunais, 2014.

ASSIS, Araken de. Processo civil brasileiro. Parte geral: fundamentos e distribuição de conflitos. São Paulo: Revista dos Tribunais, v. I, 2015.

BANDEIRA DE MELLO, Celso Antônio. Curso de Direito Administrativo. 29. ed. São Paulo: Malheiros, 2011.

BARBOSA MOREIRA, José Carlos. A motivação da sentença como garantia inerente ao Estado de Direito. Revista da Faculdade de Direito UFPR. Curitiba, dez. 1979. Disponível em: https://revistas.ufpr.br/direito/article/view/8836. Acesso em: $01 \mathrm{dez} .2019$.

BARBOSA MOREIRA, José Carlos. Tutela jurisdicional dos interesses coletivos ou difusos. In: Temas de Direito Processual. 3. ed. São Paulo: Saraiva, 1984.

BARBOSA MOREIRA, José Carlos. Comentários ao Código de Processo Civil. 16. ed. Rio de Janeiro: Forense, v. V, arts. 476 a 565, 2011. 
BENEDETTI, Miguel Ángel; SÁENZ, María Jimena. Las audiências públicas de la Corte Suprema: apetura y limites de la participación ciudadana em la justicia. Buenos Aires: Siglo Veintiuno, 2016.

BENJAMIN, Antônio Herman V. A insurreição da aldeia global contra o processo civil clássico: apontamentos sobre a opressão e a libertação judiciais do meio ambiente e do consumidor In: MILARÉ, Édis (coord.). Ação civil pública - Lei 7.347/85: reminiscências e reflexões após dez anos de aplicação. São Paulo: Editora Revista dos Tribunais, 1995, p. 78.

BONíCIO, Marcelo José Magalhães. Princípios do processo no novo Código de Processo Civil. São Paulo: Saraiva, 2016.

BRASIL. Lei no 1.060, de 5 de fevereiro de 1950. Estabelece normas para a concessão de assistência judiciária aos necessitados. Disponível em: http://www.planalto.gov.br/ccivil_03/leis/l1060. htm. Acesso em: 12 set. 2019.

BRASIL. Lei no 7.347, de 24 de julho de 1985. Disciplina a ação civil pública de responsabilidade por danos causados ao meio-ambiente, ao consumidor, a bens e direitos de valor artístico, estético, histórico, turístico e paisagístico (VETADO) e dá outras providências. Disponível em: http://www.planalto.gov.br/ccivil_03/ Leis/L7347 orig.htm. Acesso em: 12 set. 2019.

BRASIL. Lei no 8.038, de 29 de maio de 1990. Institui normas procedimentais para os processos que especifica, perante o Superior Tribunal de Justiça e o Supremo Tribunal Federal. Disponível em: https://www.direitohd.com/lei-8038-90. Acesso em: 12 set. 2019.

BRASIL. Lei $n^{\circ}$ 8.078, de 11 de setembro de 1990. Dispõe sobre a proteção do consumidor e dá outras providências. Disponível em: http://www.planalto.gov.br/ ccivil_03/leis//8078.htm. Acesso em: 12 set. 2019.

BRASIL. Lei no 9.868, de 10 de novembro de 1999. Dispõe sobre o processo e julgamento da ação direta de inconstitucionalidade e da ação declaratória de constitucionalidade perante o Supremo Tribunal Federal. Disponível em: http://www.planalto.gov.br/ccivil_03/leis//9868.htm. Acesso em: 12 set. 2019.

BRASIL. Lei no 13.105, de 16 de março de 2015. Código de Processo Civil. Disponível em: http://www.planalto.gov.br/ccivil_03/_ato2015-2018/2015/lei/ 113105.htm. Acesso em: 12 set. 2019.

BRASIL. Senado Federal. Código de Processo Civil e Normas Correlatas. 7. ed., atual. até abr./2015. Brasília: Senado Federal, 2015, p. 29. Disponível em: https://www2.senado.leg.br/bdsf/ bitstream/handle/id/512422/001041135.pdf. Acesso em: 10 dez. 2018.

BUENO, Cassio Scarpinella. Amicus curiae no Processo Civil brasileiro: um terceiro enigmático. 3. ed. São Paulo: Saraiva, 2012. 
BUENO, Cassio Scarpinella. Novo Código de Processo Civil anotado. São Paulo: Saraiva, 2015.

BUENO, Cassio Scarpinella. Quatro perguntas e quatro respostas sobre o amicus curiae. Disponível em: http://www.scarpinellabueno.com/images/textospdf/022.pdf. Acesso em: 25 jul. 2016.

BUENO, Cassio Scarpinella. Novo Código de Processo Civil Anotado. 3. ed. São Paulo: Saraiva, 2017.

BUENO, Cassio Scarpinella. Curso sistematizado de Direito Processual Civil: procedimento comum, processos nos tribunais e recursos. 8. ed. São Paulo: Saraiva Educação, 2019, versão eletrônica.

BUZAID, Alfredo. A crise do Supremo Tribunal Federal. Estudos de Direito. São Paulo: Saraiva, 1972.

CABRAL, Antonio do Passo. A escolha da causa-piloto nos incidentes de resolução de processos repetitivos. Revista de Processo, v. 231, maio. 2014 (versão digital).

CALAMANDREI, Piero. Processo e democracia: conferências realizadas na Faculdade de Direito da Universidade Nacional Autônoma do México. Trad. Mauro Fonseca Andrade. 2. ed. Porto Alegre: Livraria do Advogado, 2016.

CÂMARA, Alexandre Freitas. Levando os padrões decisórios a sério: formação e aplicação de precedentes e enunciados de súmula. São Paulo: Atlas, 2018.

CAPPELLETTI, Mauro. Juízes legisladores? Trad. de Carlos Alberto Álvaro de Oliveira. Porto Alegre: Sergio Antonio Fabris, 1999.

CAPPELLETTI, Mauro; GARTH, Bryant. Acesso à justiça. Trad. de Ellen Gracie Northfleet. Porto Alegre: Fabris, 1988.

CARMIGNANI, M. C. O direito judiciário lusitano - os assentos da casa da suplicação. Revista da Faculdade de Direito. Universidade de São Paulo, n. 111, 2017, pp. 19-29, p. 24. Disponível em: http://www.revistas.usp.br/rfdusp/article/ view/133541. Acesso em: 28 jun. 2019.

CINTRA, Antonio Carlos de Araújo; GRINOVER, Ada Pellegrini; DINAMARCO, Cândido Rangel. Teoria geral do processo. 26. ed. São Paulo: Malheiros, 2010.

CNJ. Conselho Nacional de Justiça. Os 100 maiores litigantes. Disponível em: http://www.cnj. jus.br/images/pesquisas-judiciarias/pesquisa_100_maiores_ litigantes.pdf. Acesso em: 22 jul. 2016.

CNJ. Conselho Nacional de Justiça. Relatório do Banco Nacional de Dados de Demandas Repetitivas e Precedentes Obrigatórios. Brasília, 2018.

CNJ. Conselho Nacional de Justiça. Consulta de precedente. Disponível em: https://www.cnj.jus.br/bnpr-web/. Acesso em: 12 set. 2019. 
CNJ. Conselho Nacional de Justiça. Justiça em números. Brasília, 2019.

COMOGLIO, Luigi Paolo. La garanzia costituzionale dell'azione ed processo civille. Padova: Cedam, 1970.

CÔRTES, Osmar Mendes Paixão. A "objetivação" no processo civil: as características do processo objetivo no procedimento recursal. Revista de Processo, v. 178, dez. 2009.

CÔRTES, Osmar Mendes Paixão. Recursos repetitivos, súmula vinculante e coisa julgada. Brasília: Gazeta Jurídica, 2018.

CÔRTES, Osmar Mendes Paixão. A reclamação é necessária para a inteireza do sistema de recursos repetitivos? Disponível em: https://www.migalhas.com.br/de Peso/16,MI312851,51045-A+ reclamacao+e+necessaria+para+a+inteireza+do+ sistema+de+recursos. Acesso em: 11 out. 2019.

COUTURE, Eduardo J. Fundamentos del Derecho Procesal Civil. 3. ed. Buenos Aires: Depalma, 1972.

CROSS, Rupert; HARRIS, J. W. Precedent in english law. Claredon Law Series. Oxford: Clarendon Press, 2004.

CRUZ E TUCCI, José Rogério. Precedente judicial como fonte do direito. São Paulo: Revista dos Tribunais, 2004.

CRUZ E TUCCI, José Rogério. O advogado, a jurisprudência e outros temas de Processo Civil. São Paulo: Quartier Latin, 2010.

CRUZ E TUCCI, José Rogério O regime do precedente judicial no Novo CPC. Revista do Advogado, n. 216, 2015, pp. 143-51.

CRUZ E TUCCI, José Rogério. Comentários ao Código de Processo Civil. Arts. 458 a 483. São Paulo: Revista dos Tribunais, v. VIII, 2016.

CRUZ E TUCCI, José Rogério; AZEVEDO, Luiz Carlos. Lições de história do Processo Civil lusitano. São Paulo: Revista dos Tribunais, 2009.

DANTAS, Bruno. Teoria dos recursos repetitivos. São Paulo: Revista dos Tribunais, 2015.

DEUTSCHER BUNDESTAG. Audiência Pública para reforma na Lei Kapitalanleger-Musterverfahrensgesetzes. Disponível em: http://www.bundes gerichtshof.de/SharedDocs/Downloads/DE/Bibliothek/Gesetzesmaterialien/17_wp/ KapMuGReform/wortproto.pdf?_blob=publicationFile. Acesso em: 11 maio $2 \overline{0} 17$.

DEUTSCHER BUNDESTAG. Protokoll Nr. 82. (Atas em alemão). Disponível em: http://www.bundesgerichtshof.de/SharedDocs/Downloads/DE/Bibliothek/Gesetzes 
materialien/17_wp/KapMuGReform/wortproto.pdf?_blob=publicationFile. Acesso em: 12 set. 2019 .

DICIONÁRIO HOUAISS DA LÍNGUA PORTUGUESA. São Paulo: Objetiva, 1986. DIDIER JÚNIOR, Fredie. Fundamentos do princípio da cooperação no Direito Processual Civil português. Coimbra: Coimbra Ed., 2011.

DIDIER JÚNIOR, Fredie. Curso de Direito Processual Civil: introdução ao Direito Processual Civil, parte geral e processo de conhecimento. 17. ed. Salvador: Jus Podivm, 2015.

DIDIER JÚNIOR, Fredie; PEIXOTO, Ravi. O art. 489, $\S 1^{\circ}$, do CPC e a sua incidência na postulação dos sujeitos processuais - um precedente do STJ. Disponível em: http://www.frediedidier.com.br/en/editorial/editorial-191/. Acesso em: 12 dez. 2019.

DIDIER JÚNIOR, Fredie; SOUZA, Marcus Seixas. O respeito aos precedentes como diretriz histórica do Direito brasileiro. Revista de Processo Comparado. São Paulo, v. 2, dez. 2015.

DIDIER JÚNIOR, Fredie. Os três modelos de Direito Processual: inquisitivo, dispositivo e cooperativo. In: CRUZ E TUCCI, José Rogério; RODRIGUES, Walter Piva (Coords.). Processo civil: homenagem a José Ignácio Botelho de Mesquita. São Paulo: Quartier Latin, 2013.

DONIZETTI, Elpídio. Curso didático de Direito Processual Civil. 19. ed. São Paulo: Atlas, 2016.

ENFAM. Escola Nacional de Formação e Aperfeiçoamento de Magistrado. Seminário: O Poder Judiciário e o Novo Código de Processo Civil. Enunciados aprovados. Disponível em: https://www.enfam.jus.br/wp-content/uploads/2015/ 09/ENUNCIADOS-VERS\%c3\%83O-DEFINITIVA-.pdf. Acesso em: 12 set. 2019.

ENUNCIADOS DO FÓRUM PERMANENTE DE PROCESSUALISTAS CIVIS. Florianópolis, 2017. Disponível em: http://civileimobiliario.web971.uni5.net/wpcontent/uploads/2017/07/Carta-de-Florian\%C3\%B3polis.pdf. Acesso em: 12 set. 2019.

FELSTINER, William L. F. et al. The emergence and transformation of disputes: naming, blaming, claiming. Law \& Society Review, v. 15, n. 3/4, Special Issue on Dispute Processing and Civil Litigation (1980-1981).

FENSTERSEIFER, Wagner Arnold. Distinguishing e overruling na aplicação do art. 489, § 1ํ, VI, do CPC/2015. Revista de Processo, v. 252, fev. 2016.

FERRAZ, Taís Schilling. Ratio decidendi $x$ tese jurídica. A busca pelo elemento vinculante do precedente brasileiro. Revista de Processo. São Paulo, v. 265, mar. 2017. 
FISS, Owen. Um novo processo civil: estudos norte-americanos sobre jurisdição, constituição e sociedade. Coord. Carlos Alberto de Salles. Tradução Daniel Porto Godinho da Silva e Melina de Medeiros Rós. São Paulo: Revista dos Tribunais, 2004.

GERHARDT, Michael D. The power of precedent. Oxford: Oxford University Press, 2008.

GIFIS, Steven H. Dictionary of legal terms: a simplified guide to the language of law. 4. ed. Barron's: Hauppauge, 2008.

GRINOVER, Ada Pellegrini. Ensaio sobre a processualidade: fundamentos para uma nova teoria geral do processo. Brasília: Gazeta Jurídica, 2016.

HÄBERLE, Peter Hesse Konrad. Estudios sobre la jurisdicción constitucional (com especial referencia al tribunal constitucional alemán). México: Editorial Porrúa, 2005.

IBDP. Instituto Brasileiro de Direito Previdenciário. Atuação judicial. IRDR 502681368.2016. 4.04.0000. Disponível em: https://www.ibdp.org.br/?p=494. Acesso em: 12 set. 2019.

ITALIA. Constituição da República Italiana. Milão: Senato dela Repubblica, 2018. Disponível em: https://www.senato.it/application/xmanager/projects/leg18/file/ repository/relazioni/libreria/novita/XVII/COST_PORTOGHESE.pdf. Acesso em: 12 set. 2019.

KELSEN, Hans. Teoria pura do direito Trad. oão Baptista Machado. 8 ${ }^{a}$ ed. São Paulo: Martins Fontes, 2009.

KLAFKE, Guilherme Forma; PRETZEL, Bruna Romano. Processo decisório no Supremo Tribunal Federal: aprofundando o diagnóstico das onze ilhas. Revista de Estudos Empíricos em Direito. Brazilian Journal of Empirical Legal Studies v. 1, n. 1, jan. 2014, pp. 89-104. Disponível em: http://www.reedpesquisa.org/ojs2.4.3/index.php/reed/article/view/8. Acesso em: 11 ago. 2016.

LEAL, Victor Nunes. Passado e futuro da súmula do STF. Revista de Direito Administrativo. Rio de Janeiro, v. 145, jan. 1981, pp. 1-20. Disponível em: http://bibliotecadigital.fgv.br/ojs/index.php/rda/article/view/43387. Acesso em: 11 nov. 2019.

LEMOS, Vinicius Silva. O incidente de assunção de competência da conceituação à procedimentalidade. Salvador: JusPodivm, 2018.

LISBOA, Aline. Participação social no controle de constitucionalidade: a propositura de ações diretas, o amicus curiae e as audiências públicas. Belo Horizonte: Fórum, 2013.

LUCON, Paulo Henrique dos Santos. Motivação das decisões jurídicas: identificação das decisões imotivadas. In: PUOLI, José Carlos Baptista; BONIZZIO, 
Marcelo José Magalhães; LEONEL, Ricardo de Barros (Coords.). Direito Processual Constitucional. Brasília: Gazeta Jurídica, 2016.

LUHMANN, Niklas. Legitimação pelo procedimento. Trad. Maria da Conceição Côrte-Real. Brasília: Universidade de Brasília, 1980.

MANCUSO, Rodolfo Camargo. Acesso à justiça: condicionantes legítimas e ilegítimas. 2. ed. São Paulo: Revista dos Tribunais, 2015.

MARINONI, Luiz Guilherme. Novas linhas do Processo Civil. 4. ed. São Paulo: Malheiros, 2000.

MARINONI, Luiz Guilherme. Incidente de resolução de demandas repetitivas: decisão de questão idêntica x precedente. São Paulo: Revista dos Tribunais, 2016a.

MARINONI, Luiz Guilherme. O julgamento nas cortes supremas: precedentes e decisão do recurso diante do novo CPC. São Paulo: Revista dos Tribunais, 2016b.

MARINONI, Luiz Guilherme. Sobre o incidente de assunção de competência. Revista de Processo, v. 260, out. 2016c, pp. 233-56 (versão eletrônica).

MARINONI, Luiz Guilherme; ARENHART, Sérgio Cruz; MITIDIERO, Daniel. Manual do processo civil. 4. ed. São Paulo: Revista dos Tribunais, 2019 (edição eletrônica).

MARTIN, Elizabeth A. Oxford Dictionary of Law. 7. ed. Oxford: Oxford University Press, 2013.

MITIDIERO, Daniel. A colaboração como norma fundamental do Novo Processo Civil Brasileiro. Revista do Advogado. São Paulo, v. 35, n. 126, maio 2015.

MORAES, Anderson Júnio Leal. Audiências públicas e legitimação da jurisdição constitucional. Belo Horizonte: Initia Via, 2012.

MORETO, Mariana Capela Lombardi. O precedente judicial no sistema processual brasileiro. Tese (Doutorado em Direito) - Faculdade de Direito. Universidade de São Paulo, 2012.

NERY JÚNIOR, Nelson; NERY, Rosa Maria de Andrade. Comentários ao Código de Processo Civil. São Paulo: RT, 2015.

NEVES, Daniel Amorim Assumpção. Manual de Direito Processual Civil. 9. ed. Salvador: JusPodivm, 2017.

NUNES, Dierle; DELFINO, Lucio. Chancela do contraditório: tribunais superiores devem ampliar debates ao formar precedentes. Disponível em: https://www.conjur.com.br/2014-set-24/tribunais-superiores-ampliar-debatesformar-precedentes. Acesso em: 10 maio 2018.

OLIVEIRA, Carlos Alberto Álvaro. A garantia do contraditório. Revista da Faculdade de Direito da UFRGS. Porto Alegre, v. 15, 1998. 
ONODERA, Marcus Vinicius Kiyoshi. Gerenciamento do processo e o acesso à justiça. Belo Horizonte: Del Rey, 2017.

PICARDI, Nicola. Jurisdição e processo. Trad. de Carlos Aberto Álvaro de Oliveira. Rio de Janeiro: Forense, 2008.

ROSAS, Roberto. Da súmula à súmula vinculante. São Paulo: Revista dos Tribunais, v. 879. Jan./2009 (versão digital).

SALLES, Carlos Alberto de. Precedentes e jurisprudência no novo CPC: técnicas decisórias. O novo Código de Processo Civil: questões controvertidas. São Paulo: Atlas, 2015.

SANTOS, Evaristo Aragão. Em torno do conceito e da forma formação do precedente judicial. In: WAMBIER, Teresa Arruda Alvim (Org.). Direito Jurisprudencial. São Paulo: Revista dos Tribunais, 2012.

SENADO FEDERAL. Projeto de Lei do Senado n. 166, de 2010. Disponível em: https://www2.cjf.jus.br/jspui/bitstream/handle/1234/45441/PL\%208046_2010.pdf?s equence=1. Acesso em: 12 set. 2019.

SILVA, Rodrigo. Guia politicamente incorreto da política brasileira. Rio de Janeiro: Leya, 2018.

SOUZA, Artur Cesar de. Código de Processo Civil: anotado, comentado e interpretado: parte especial (arts. 693 a 1.072). São Paulo: Almedina, v. III, 2015a.

SOUZA, Artur Cesar de. Resolução de demandas repetitivas. São Paulo: Almedina, 2015b (versão eletrônica).

STF. Supremo Tribunal Federal. Audiências públicas realizadas. Disponível em: http://www.stf.jus.br/portal/audienciaPublica/audienciaPublica.asp?paginaAtual=1 \&tipo=realizada. Acesso em: 8 dez. 2019.

STJ. Superior Tribunal de Justiça. Aglnt na Pet 11.838/MS. Rel. ministra Laurita Vaz, Rel. p/Acórdão ministro João Otávio de Noronha, Corte Especial, julgado em 07/08/2019, DJe 10/09/2019.

STJ. Superior Tribunal de Justiça. Decisão Monocrática REsp 1635428-SC (2016/0285000-5), j. 01/08/2018. Disponível em: https://stj.jusbrasil.com.br/ jurisprudencia/607382479/recurso-especial-resp-1635428-sc-2016-0285000-5.

Acesso em: 12 set. 2019.

STJ. Superior Tribunal de Justiça. Decisão Monocrática Resp no 1419697-RS (2013/0386285-0), j. 04/06/2014. Disponível em: https://www.conjur.com.br/dl/ primeira-audiencia-publica-stj.pdf. Acesso em: 12 set. 2019.

STJ. Superior Tribunal de Justiça. PET no REsp 1551956/SP. Rel. min. Paulo de Tarso Sanseverino, j. 15/04/2016. 
STJ. Superior Tribunal de Justiça. Proposta de Afetação no Recurso Especial. ProAfR no REsp 1799343/SP. Disponível em: https://sti.jusbrasil.com.br/ jurisprudencia/698753759/proposta-de-afetacao-no-recurso-especial-proafr-noresp-1799343-sp-2018-0301672-7. Acesso em: 12 set. 2019.

STJ. Superior Tribunal de Justiça. Proposta de Afetação no Recurso Especial: ProAfR no REsp 1610728/RS - 2016/0171099-9. Disponível em: https://stj.jusbrasil.com.br/jurisprudencia/574632908/proposta-de-afetacao-norecurso-especial-proafr-no-resp-1610728-rs-2016-0171099-9/inteiro-teor574632918. Acesso em: 12 set. 2019.

STJ. Superior Tribunal de Justiça. Recurso Especial 1604412/SC/2016/0125154-1. Disponível em: https://stj.jusbrasil.com.br/jurisprudencia/616331240/ recursoespecial-resp-1604412-sc-2016-0125154-1/relatorio-e-voto-616331253? ref=juristabs. Acesso em: 12 set. 2019.

STJ. Superior Tribunal de Justiça. Recurso Especial n. 1067237/SP. Rel. ministro Luis Felipe Salomão, Segunda Seção, julgado em 24/06/2009, DJe 23/09/2009. Disponível em: https://ww2.stj.jus.br/processo/revista/documento/mediado/? componente=ITA\&sequencial $=897656 \&$ num_registro $=200801159861 \&$ data $=2009$ 0923\&formato=PDF. Acesso em: 12 set. 2019.

STJ. Superior Tribunal de Justiça. Recurso Especial n. 911.802-RS. Disponível em: http://www.mp.go.gov.br/portalweb/hp/4/docs/stj_telefonia_assinatura_basica. pdf. Acesso em: 12 set. 2019.

STJ. Superior Tribunal de Justiça. Recurso Especial. REsp 1419697-RS, 2013/0386285-0. Decisão monocrática de 04/06/2014. Disponível em: https://stj.jusbrasil.com.br/jurisprudencia/ 152068666/recurso-especial-resp1419697-rs-2013-0386285-0/relatorio-e-voto-152068681. Acesso em: 12 set. 2019.

STJ. Superior Tribunal de Justiça. Recurso Especial. REsp 1610728 RS 2016/0171099-9. Disponível em: https://stj.jusbrasil.com.br/jurisprudencia/ 503149584/recurso-especial-resp-16107 28-rs-2016-0171099-9. Acesso em: 12 set. 2019.

STJ. Superior Tribunal de Justiça. REsp 1106654 RJ, Rel. Ministro Paulo Furtado, Segunda Seção, julgado em 25/11/2009, DJe 16/12/2009. Disponível em: https://stj.jusbrasil.com.br/ jurisprudencia/6218318/recurso-especial-resp-1106654rj-2008-0261750-0/inteiro-teor-12347002? ref=juris-tabs. Acesso em: 12 set. 2019.

STJ. Superior Tribunal de Justiça. REsp 1631846/DF. Rel. ministro Paulo de Tarso Sanseverino, Rel. p/Acórdão ministra Nancy Andrighi, Terceira Turma, julgado em 05/11/2019, DJe 22/11/2019.

STJ. Superior Tribunal de Justiça. REsp 951894-DF (2007/0108079-4), j. 26/10/2015. Disponível em: https://ww2.stj.jus.br/processo/pesquisa/. Acesso em: 12 set. 2019. 
STJ. Superior Tribunal de Justiça. Súmulas. Disponível em: http://www.stj.jus.br/ docs_internet/VerbetesSTJ_asc.pdf. Acesso em: 12 set. 2019.

TARUFFO, Michele. Dimensiones del precedente judicial. In: Páginas sobre justicia civil. Madrid: Marcial Pons, 2009.

TARUFFO, Michele. Precedentes e jurisprudência. Revista de Processo. São Paulo, v. 199, set. 2011.

TARUFFO, Michele A motivação da sentença civil. Trad. de Daniel Mitidiero. São Paulo: Marcial Pons, 2015.

TARUFFO, Michele; HAZARD Jr. Geoffrey C. American civil procedure: an introduction. Yale University Press: New Haven,1993.

TEMER, Sofia. Incidente de resolução de demandas repetitivas. Salvador: JusPodivm, 2016.

THEODORO JÚNIOR, Humberto. Curso de direito processual civil: teoria geral do direito processual civil, processo de conhecimento e procedimento comum. 56. ed. Rio de Janeiro: Forense, v. I, 2015.

THEODORO JÚNIOR, Humberto. Curso de Direito Processual Civil: execução forçada, processo nos tribunais e direito intertemporal. 49. ed. Rio de Janeiro: Forense, v. III, 2016.

TJ/SP. Tribunal de Justiça de São Paulo. Incidente de Resolução de Demandas Repetitivas. Processo n. 2065868-32.2016.8.26.0000. Relator: Paulo Barcellos Gatti. Data de julgamento: 26/08/2016. Turma Especial - Público, Data de Publicação: 30/08/2019.

TJ/SP. Tribunal de Justiça de São Paulo. Incidentes de Resolução de Demandas Repetitivas. Incabíveis, Inadmitidos e Pendentes. Processo n. 2084075-79.2016. 8.26.0000. Atualizado em: 16 dez. 2019. Disponível em: http://www.tjsp.jus.br/ Download/Portal/Nugep/Irdr/IrdrsInadmitidos. pdf. Acesso em: 12 set. 2019.

TROCKER, Nicolò. Processo civile e costituzione: problemi di diritto tedesco e italiano. Milano: Giuffrè, 1974.

VIANA, Aurélio; NUNES, Dierle. Precedentes: a mutação no ônus argumentativo. Rio de Janeiro: Forense, 2018.

WAMBIER, Teresa Arruda Alvim. A vinculatividade dos precedentes e o ativismo judicial - paradoxo apenas aparente. DIDIER JR., Fredie et al. (Coord.). PRECEDENTES. Salvador: Judpodivm, 2015.

WAMBIER, Teresa Arruda Alvim. Interpretação da lei e de precedentes: civil law e common law. São Paulo: Revista dos Tribunais, v. 893, mar. 2010 (versão eletrônica). 
WAMBIER, Teresa Arruda Alvim. Distinção entre questão de fato e questão de direito para fins de cabimento do recurso especial. Revista de Processo. Vol. 92/1998. Outubro de 1998.

WAMBIER, Teresa Arruda Alvim. Precedentes e evolução do Direito. In: Direito Jurisprudencial. Obra coletiva de Teresa Arruda Alvim Wambier. São Paulo: Revista dos Tribunais, 2012b.

WAMBIER, Teresa Arruda Alvim (Coord.). Breves comentários ao novo Código de Processo Civil. São Paulo: Revista dos Tribunais, 2015.

WAMBIER, Teresa Arruda Alvim (Coord.). Primeiros Comentários ao Novo Código Civil. 2. ed. São Paulo: Revista dos Tribunais, 2016.

WAMBIER, Teresa Arruda Alvim; DANTAS, Bruno. Recurso especial, recurso extraordinário e a nova função dos tribunais superiores no direito brasileiro. 3. ed. São Paulo: Revista dos Tribunais, 2016.

WATANABE, Kazuo. Acesso à justiça e sociedade moderna. In: GRINOVER. Ada Pellegrini (Coord). Participação e processo. São Paulo: Revista dos Tribunais, 1988.

WATANABE, Kazuo. Cultura da sentença e cultura da pacificação. In: SALETTI, Achille (Org.). Estudos em homenagem à Professora Ada Pelegrini Grinover. São Paulo, 2005.

YARSHELL, Flávio Luiz. Curso de Direito Processual Civil. São Paulo: Marcial Pons, v. I, 2014. 
